\title{
The Ritual Dance of Cangyuan
}

\author{
Yaping Qiu ${ }^{1, a}$ \\ ${ }^{1}$ Department of dance, School of Arts, Yunnan University of Nationalities, 650500 \\ a Qiuyaping650500@126.com
}

Key words: Cangyuan, wa, dance, dance research, culture;

\begin{abstract}
Cangyuan County, Lincang City, Yunnan Province is one of Chinaonly two Wa Autonomous County, is China's largest minority populated counties, the wa population accounts for the county has a population of nearly 9 percent, accounting for more than $4 \%$ of the Wa Nationality in China with a total population of, is a well deserved World Wa Xiang and the World Wa culture. It is the largest county wa settlements, because of the problems of modern society, and in the past long-term traffic inconvenience information occlusion of the wa culture is well preserved, is a blend of well deserved wa cultural origin and wa culture, this paper in order to wa dance collect and analysis.
\end{abstract}

\section{Cangyuan, WA dance ceremony introduction}

Cangyuan, the introduction of a ritual danceThe folk dance throughout the religious ritual, funeral, festivals and other activities. Traditional festivals are: the Spring Festival, pulling wooden drum Festival, new water Festival, new Fire Festival, SA Valley Festival, new rice festival etc.; Buddhist Festival: pile of sand section, section closed and open sections. In various types of activities. These folk dances, all wa. The main dance: dance, drum worship ZiYuXing dance, dance, dance and celebrate Buddhist funeral dance. Formed in the traditional wa sacrifice life, production and labor 13 kinds of folk dance, mainly include: wooden drum, mourning dance, mortar dance bar, pull wooden dance, sword dance, dance Sanxian, bee barrel encouraged, Dage, Bi song dance, swing dancing, music dance, Lusheng dance etc.. A total of more than 70 kinds of jump method. The main features of the wa dance is: lower limb movements are complicated, dance changes, double stamping single kick, stamp, stamp, three steps at a kick, step kick, leg Liao according to, these characteristics formed the folk dances of the VA strength is strong, bold and unconstrained, straightforward, simple and vigorous style.

\section{Cangyuan, WA main ritual dance Cangyuan wa dance 13 dances are as follows:}

The generations lived in the Lancang River west of the east coast of Nu River, the Nu mountains south zone. With strong perseverance Wa national character, a common belief of all things a primitive religion, the wooden drum, rob cattle worship, worship are unique headhunting primitive religious sacrificial activities. The Wa nationality of the deceased and comfort relatives of the dead have fame and jump custom dance. It is popular in South La Xiang and fellow class area. The old man said: "life and love to sing love dance, dance with the dead also." the people said: "the dead should not cry, cry in the sounds like a crow call, unlucky, to sing with cry to comfort relatives of the deceased, also can comfort the soul, that is to welcome him, happy dance. No musical accompaniment, but by a chorus of dancers, dancers, a circle, hand in hand, in the face of the coffin dance movement from beginning to end only on foot, Leg, body slightly bent and stepping, straight body five movements. Wa this both for the living happy, to comfort the souls of the deceased funeral dance, with the cohesive Role, and has been in Wa village heritage.

Chung handheld (. Hold a memorial ceremony for the men and women on collective pounding rice. As a memorial of the stockade with cattle nimble jump collective dance. The dance, bamboo, bells to the accompaniment of Chung rods (for husking rice) represents a eat, wear, bamboo said 
housing, bells potato said horse riding. Accompaniment is in duple time. No lyrics and dance moves, lightweight flexible. Several women Chung stick around pestle jump, turning action, issued at the same time, "ah ah", "ah ha!" cries. The old walled die, such as diagrams are not good, also want to dance this dance.

Waxy good along the wooden bridge in the process of jump and dance group, which contains two ritual customs and entertainment content and the dance by pulling the wooden bridge and knife dance is composed of two parts. Dance dancers stand in a few character, singing with a wooden bridge rattan rope pulling edge dance edge, without the accompaniment of musical instruments. Lyrics effect is to pray to the wooden bridge can safely reach the destination. After the completion of the bridge, pig slaughtering cattle when the two men in the elephant foot drum, cymbals, Mang, Gong musical accompaniment jump double sword dance. Wudao rigid flexible, efforts with the rhythm of accompaniment music intensity changes.

Spread in the vicinity of the old class a self-defense folk sabreplay, dance is a collective male dance, from Dai area descendants. Sword dance by squat step left knee kneel earthquake, right knee kneel earthquake that left Shangbu left knee kneel earthquake, Shangbu right right knee kneel earthquake five parts. Without the accompaniment of musical instruments, generally only in the major festival show has become martial arts.

Wa ancestral a regardless of seasonal and entertainment group dance. In the moonlight no singing tune, with three stringed accompaniment of dance, dance vigorous and effective action, natural and unrestrained, freely. Dance boosting, lyric, which belongs to the minor mode music. Young men and women often dance and mutual v. Zhongqing.

With the content and nature of the three stringed dance is largely the same, also belongs to the wa ancestral a non seasonal dance. Dance the harmonica is made of sawali harmonica accompaniment, men and women youth collective entertainment dance, dance vigorous and effective action, just soft, soft in the band just, dance is fresh, cheerful.

Translation of Chinese to "jump enclosure". It is wa ancestral with Bi song (i.e. straight flute accompaniment), regardless of the season, time hopping and entertainment and collective dance, dance when playing in the middle edge blowing edge jump, the other dancers in the periphery into a circle hand in hand with cries of dancing to the rhythm of the music and dance cheesy, freely, wild, uninhibited.

Spread in the old class, Banhong, a male and female masturbation collective dance south LA area. With the descendants of Theravada Buddhism, closed only in the water sprinkling Festival, a jump open day. The difference with the pendulum swing dancing of Dai jump is the biggest jump: Dai pendulum is part of the male collective dance, with drum, drum, cymbal accompaniment. Swing dancing is belong to the men and women of the collective dance, men and women both inside and outside the two ring, handle counterclockwise circle dance. In bee drum, drum, cymbals accompaniment of dance. Dance beats random and improvisation. No great music accompaniment song and dance is the traditional song and dance entertainment. It is divided into male and female children dance, female children dance, three types of young female group dance. Boys and girls dance in the form of the game is children's dance, the form of lively, vivid. Basic steps: step, tic, and ceiling, knees leg movements are more, the basic gestures: beckon with the hand, palm of the hand, arm swing, as a free action casual. Knees ceiling legs, turn half a circle, kick his arms back and forth along the swing dance moves the main characteristics.

Lusheng dance in the South $\mathrm{Xu}$ existing many ethnic folk activities. The Lusheng dance and other ethnic groups, but also by the name. The Lusheng accompaniment Lusheng dance in general holidays when jumping, dancing venues in the courtyard, in the evening, a bonfire, people danced in the lead dancer flutist. For men and women with the most popular folk dance of the collective, is generally in the Chinese Lunar New Year jump, only Lu Wang dance accompaniment, dancers also wrote lyrics while shouting match. There are 50 kinds of Lusheng dance and dance accompaniment. Jumping Lusheng dance movements rich, and the basic law of the myriads of changes, consistent performance: left the right leg started on foot, stamp, knees, more or less. The steps generally first left, step left light right, a flick. Combination of strong symmetry, are generally left one, right once, 
before once, after a dance. Also tend to be men and women into Larger close. Light entertainment wa has. Lyrics to sing and dance is also very harmonious, improvisation with a distinct rhythm of Sheng sound, the dance in a warm atmosphere and order wa Lusheng dance held each year, is the elimination of fatigue, unity ahead of the dance. The common characteristic is: Jumping stomp force is strong, to his left foot, right foot, hand movements to carry a natural droop, and sway to and fro in the formation for facing the counterclockwise direction of circle, a clockwise direction regress, retreat style to the center of the circle. The dance to casual and improvisation, dance clear, forthright, resolute, simple, content is the performance of the Wa people, love life, love of his hometown.

Chung Pestle Dance from labor life action, this dance for dancers holding bar around the grain filled with mortar and pestle nest dance, dance without musical accompaniment, all by the dancers with mortar stick percussion sound rhythm as the stone mortar dance. Dance dance is Chung pestle to extract on weekdays tsuishine work. On the basis of tsuishine labor movement by the waist awesome support, hold hands and arms to knock the pestle. On this basis, the dancers were exaggerated to action, in the arms of tsuishine and do the action, with the body bent back before the swing, graceful posture and the waist moves, the dance shows the characteristics of simple and generous, warm and cheerful. Chung Pestle Dance is the most widely circulated in the Wa, the most popular, almost every village will dance. After the liberation, "Chung Pestle Dance $>$ processed, after finishing has been moved to the art scene, screen, electric The visual.

Is one of the widely circulated in the Wa village in the oldest and most representative folk dance. When craftsmen took the wooden drum is made after try knocking satisfied, carried into the wooden drum room shelves. Then they can't wait to essential hammer beat. Dance dance. Men and women can participate, the number is not limited. The main plot is shuttle head into the wooden drum room, with sadness, pious singing. At the beginning of the relatively low and slow; after his head sent to the drum room, the atmosphere lively, intense. wa mountain group dance "and so on inherited the outstanding elements of the wa dance, reflecting the wa brave, brave and extensive, simple national character, image performance to enter the socialist society in the period of the Wa People's spirit. Dance percussion drum a sonorous and forceful characteristics of sound and full of change of rhythm, with rough mad, aerobics, rhythmic chic movement is fiery and passionate emotional dance.

The young woman is their hair swinging dance dance popular in Yunnan Cangyuan, Ximeng area of each village in wa. The dance is a young woman to the world that she grew up to be mature, to dance long hair to attract the opposite sex. The women and women of Dai, amoda long hair, black hair flip blowing, fully display the charm of women. After the girl in the bamboo from their hair swinging dance wa groove hair, combing and exposed to the weather live action. You can dance and dance, dance, "rejection hair" as the main feature of the dance. Cangyuan their hair swinging dance in general in the wind clear pale blue evening time hopping, VA girls hand in hand the enclosure to dance, to sing the lyrics is: "bright moon, moon, moon follow Baiyun, singing and dancing happy." Dance basic action: step with their hair swinging dance movement combination spring, that the right foot to the right lateral six steps, then left foot left shifting the hexapod, then both legs to stand straight, leaning forward and forward at the same time the hair flip. Double arm swing, then the legs slightly bent, upper body slightly upward, his half clenched fists thrown forward to the ear, and back hair flip. So the action is repeated, then legs slightly bent, slightly out of left hip, rightist body backwards, the rise of visual motion at the upper left, and then do the opposite action, the hair take a forward, after the rejection twice, body with before bent over Yang. A shot of a forward hair flip six times, after the body is straight hair flip backwards. The dance accompaniment, with song, repeated. Is a dance spread widely in the wa women. Their hair swinging dance become represent the wa dance, the original ecological folk song and dance is professional engaged in the art of dancing mining finishing adaptation become ornamental strong wa folk dance and popular.

It is also southwest of many ethnic minorities are some folk dance. But different people have different ceremonies Dage characteristics. Wa Dage in marriages, funerals, holiday leisure hop, it is not limited by space, number and time; form of singing and dancing, performing style, warm and 
cheerful. Is the performance of the production and life of people with feelings of joy, and pray for good weather, a bumper grain harvest content. As Dage accompaniment instruments: Flute, erhu, hulusheng, Bi song, instrument, and rod of Xiao gu. Dage it "high", the dancers form a circle, hand in hand, into a retreat, swing, first three beats lighter delay, the fourth force, dance rhythm fast. The flute accompaniment, a person singing. People do arm hang down with the dance moves before and after the swing dance, dance basic action: right foot forward to take a step forward, from the left foot forward two steps, from the left foot forward three steps. Step two step forward from the right foot, while the right foot forward, while the left foot forward kick to the right foot next to the right foot, take advantage of the left turn 1/4 laps. Feet are stepping a jump forward one step, landing left in front, right foot after the squat, then right foot left foot, with the body erect, then slow double speed feet stepping a jump forward one step,

\section{The significance of the ritual dance}

"Wa of original ecology dance, not simple primitive dances or folk dance, is not a simple dance movements of the heap and form or biography, but a whole life state of the presentation." [1] they believe that everything has a spirit, people need to communicate with heaven and earth, all things and gods, and dance is the only way to communicate with all things. Dance is not an act, but their way of life, and the life dance not to stage performances and human creation of, it is because of its deep origin has become a social life, the meaning of some of the rituals of the has become part of the local people's life. The costumes and dances of this kind of dance have distinct regional national characteristics, and they have certain ancient meanings. The native dance fully reflect the nature of life, WA dance is a part of the folk life and production activities, it as the content of human activities exist in mass, it with folk life based, dance expression of life needs.

The dance is an age-old, a folk phenomenon of people's lives, production and psychological deep impact. When the strong desire to conquer and control the natural world is hard to realize because of the lack of means, the grand ceremony dance began. They have a strong sense of their own existence value through this ritual dance, and they are aware of their huge potential initiative with the group. Wa of original ecology dance as a live painting scroll of history, to the people tell the primitive way of life, reflect their reverence for the gods, the life. The connotation of the dance movements, the expression of the dance of the dance, as well as the sacred meaning of dance and its role of living fossils, have a high artistic value. Original ecology dance WA, the rendering process is performing arts; dance of the specific time, space and connotation reflects the age of folk festivals and rituals of life; and dance clothing and specific tools and related special fabrication technology are closely related. So, the original dance is a very rare form of art. This dance is dancers from generation to generation from the fathers inherited and has the life vitality, can continue to develop live state of culture and art. Wooden drum dance is wa folk most cohesive, the most primitive, rough, uninhibited, stirring, passion, flying dance, is a typical representative of the wa prehistoric folk dance, is the valuable remains of primitive dance is source of Wa nationality traditional song and dance art; wa history and culture is a symbol, is a representative of the wa culture. May 2006 "wa muguwu" by the State Council announced the first batch of national intangible cultural heritage list.

Wa original ecological their hair swinging dance contains deep cultural connotation, it is an organic part of the Wa of original ecology dance. This dance to the nature of the initial in the original state of dance can be now, it's time to wake up our blood for a nation's primary memory, fully demonstrated the wa beautiful girl honest, diligent and kind character. Dance with emotion, dance of the gods of both. Not only give a person a kind of visual sense of beauty, but also give a person a kind of original heart touch. It strengthens the group consciousness of the clan society, family system, degree of condensed people, unite the people, and enhance the Wa People's national pride and a sense of identity, to let the Wa people in different levels, different understanding, find a harmonious community life of the social order. In addition, it also played a certain role in social education. Wa original ecological their hair swinging dance to a culture, a kind of unwritten religious, a worship of the way, and gradually evolved into the "love" of the Confucianism culture 
and the spread of the folk custom. In full commercial and foreign powerful culture constantly involved in today, their hair swinging dance, as a branch of original ecology dance WA, an important part, by the original since the songs from the dance without the accompaniment of musical instruments, don't climb repeating entertain program, is to move our literary and art workers on the literary scene. And get the support of government departments, the original ecological their hair swinging dance Wa is the fulcrum of the sustainable development, now with the wa original ecology dance representative of their hair swinging dance has known both inside and outside, "their hair swinging dance" swept the country. This is a new it brings strong vitality and unprecedented brilliant stage art. In our vigorous development of the cultural heritage and intangible cultural heritage protection, only respect and fear of the earth shaking the hair of the black ghost. To protect her, to inherit her, to develop her.

\section{The conclusion}

The cultural resources at home and abroad have more advantages in resources, which is different from the other local characteristic resources. Located in China's southwest border, WA is less populous nation in history. The settlement is still lagging infrastructure and backward economy. Whether the wa culture or natural resources, it has the advantage of original ecology. Wa mountain is the largest county wa settlements, due to social problems and the past long-term traffic inconvenience, information occlusion the wa culture is well preserved, is worthy of the wa culture origin and wa culture blend. For thousands of years, people in the wa wa on this piece of land, created a brilliant and unique culture. Here is the art of human childhood, cliff painting, and day dialogue artifact -- wa wooden drum, used in the hair of love - wa Characteristic Dance "their hair swinging dance", China finally a tribe -- Ding Weng, combustion passion of Oriental Carnival -touch you black, its tourism cultural industry is the soul of unique wa culture.

China is renowned the world's cultural shrine, the long history of the gave birth to the diverse ethnic cultures, a wide geographical region bearing the variety of national culture, the enthusiasm of the people of all ethnic groups passing all kinds of national culture, love and faithfulness of the Communist Party of China care of infinite national culture, in the peace of the world, national culture growing and prosperity, tile culture is with with the culture steps out of the region and to the world.

\section{Reference}

[1] Square Fuyi. Cultural linguistics. Wuhan: Hubei Education Press, 1990,22 